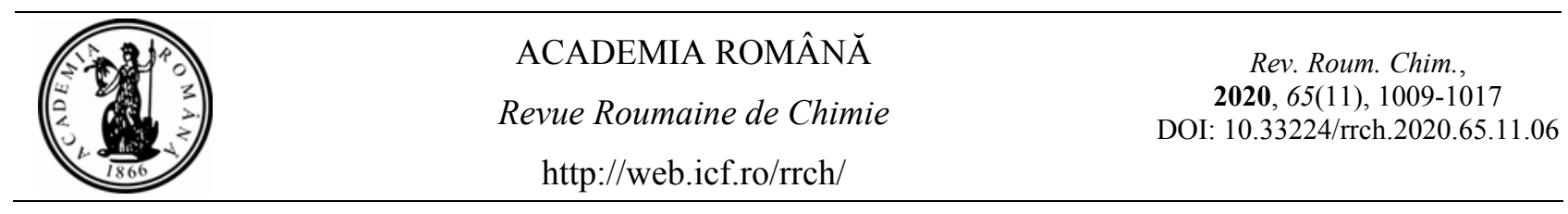

\title{
DIELECTRIC PROPERTIES OF SOME POLYMERS/ METAL OXIDE NANOPARTICLES NANOCOMPOSITES USING FAST TECHNIQUE
}

\author{
Fatma Zohra BENABID, ${ }^{\mathrm{a},{ }^{*}}$ Foued ZOUAI ${ }^{\mathrm{b}}$ and Djafer BENACHOUR ${ }^{\mathrm{a}}$ \\ ${ }^{a}$ LMPMP, Faculty of Technology, Ferhat ABBAS University Sétif-1, Algeria \\ ${ }^{\mathrm{b}}$ Emerging Materials Research Unit, Ferhat ABBAS University Sétif-1, Algeria
}

In this study, a comparative study of nanocomposites with treated and untreated metal oxide nanoparticules using a plastograph was investigated. Stearic acid and co-mixing technique were chosen as a fast technique to ensure the dispersion of the filler into the polymeric matrix. Fillers were mechanically treated and co-mixed with stearic acid using kitchen coffee grinder and the mixture was then added to the polymeric matrix in a Brabender plastograph with various contents of 0.5 wt. $\%, 1$ wt. $\%$ and 2 wt. $\%$. The method effectiveness has been proved by AFM analysis.

The results showed that the incorporation of inorganic semiconductor nanoparticles into polymeric matrix improves the dielectric properties. Results showed that with the co-mixing process and stearic acid the inorganic nanofillers have a strong influence on the permittivity of resulting nanocomposites.

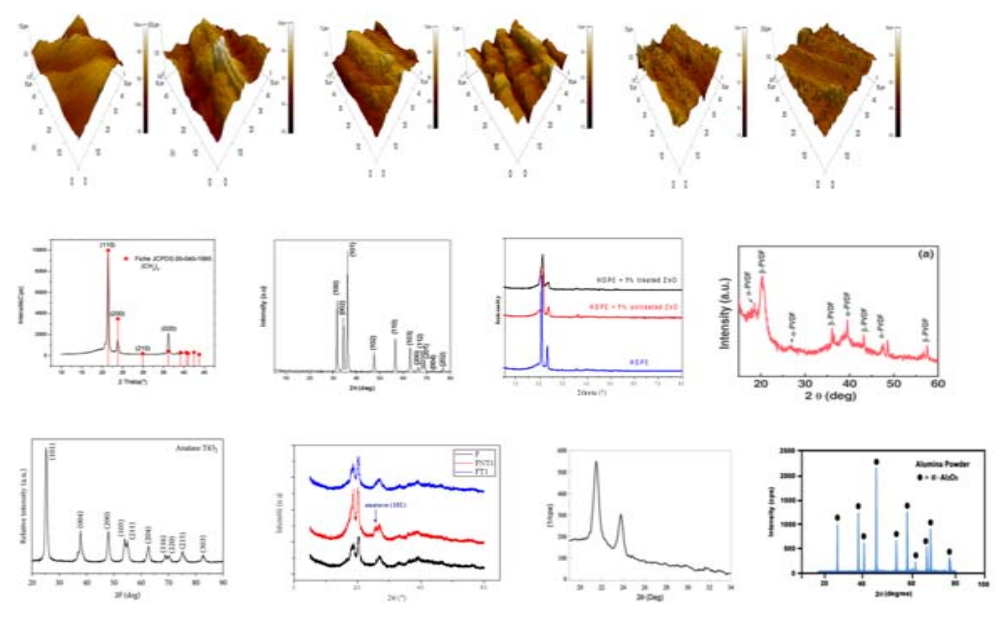

\section{INTRODUCTION}

Nowadays, the term polymer composite is used to describe materials which consist of one or more fillers and one, or a blend of, polymers. Nanocomposites lead to an enhancement of mechanical, thermal and electrical properties of basic polymers. ${ }^{1}$ The development of metal oxides has revitalized nanocomposite science and technology leading to the evolution of a new generation of materials.

Metal oxides have an important role in many areas of chemistry, physics and materials science.
Attention in the Al-O system is centered in the $\mathrm{Al}_{2} \mathrm{O}_{3}$ stoichiometry. There are seven $\mathrm{Al}_{2} \mathrm{O}_{3}$ polymorphs, although only four of them called $\alpha$, $\delta, \theta$, and $\gamma$, are typically involved in most of the industrial processes. ${ }^{2}$ Alumina $\mathrm{Al}_{2} \mathrm{O}_{3}$ was selected as filler for the LDPE due to its excellent dielectric properties. ${ }^{3}$ The Ti-O bond increases the covalent character with the oxygen content of the oxide. $\mathrm{TiO}_{2}$ occurs in nature in three different polymorphs which, in order of abundance, are rutile, anatase, and brookite. ${ }^{4}$

The excellent optical and electrical properties of $\mathrm{ZnO}$ make it a useful material for producing

\footnotetext{
${ }^{*}$ Corresponding author: fzbenabid@yahoo.fr
} 
voltage dependent resistor and image recording. The wide band gap and large excitonic binding energy have made zinc oxide important, both, for scientific and industrial applications. ${ }^{5,6}$

Metal nanoparticles elaboration and characterization constitute a major research area in polymer chemistry and nanotechnology fields. Many research works suggested that addition of inorganic nanofiller into the polymer deals with the enhancement of polymer properties, which greatly differ from the conventional polymer ones exhibit unexpected properties. ${ }^{7-9}$

On the other hand, the PVDF is a polar polymer with excellent properties, usually used blended with other polymer in order to improve some properties ${ }^{10}$ or with the clay as nanocomposites. ${ }^{11}$

The main challenge in the preparation of nanocomposites is the nanoparticules dispersion. Generally, nanoparticules have the tendency to aggregate into the polymeric matrix. For this reason and in this context, we have used the comix method and the stearic acid in order to ensure the dispersion of the nanofillers.

Nanocomposites polymers/ metal oxides were elaborated using a plastograph in the presence of nanoparticles as $\mathrm{ZnO}, \mathrm{TiO}_{2}$ and $\mathrm{Al}_{2} \mathrm{O}_{3}$. $\mathrm{HDPE} / \mathrm{ZnO}$ nanocomposites have many industrial applications such as food packaging, drug and pharmaceutical bottles. $\mathrm{LDPE} / \mathrm{Al}_{2} \mathrm{O}_{3}$ nanocomposites are always used for the cable industry, or as electrets, electrooptics, surface modification, electrical insulation, nuclear physics and space industry. On the other hand, $\mathrm{PVDF} / \mathrm{ZnO}$ nanocomposites are utilized in different industries, especially in textile and polymers or as high-k capacitors.

\section{EXPERIMENTAL}

\section{Materials}

In this work the used materials are:

- High density polyethylene HDPE (HYA 600) with a density of $0.95 \mathrm{~g} / \mathrm{cm}^{3}$ and a melt flow index of $4.2 \mathrm{~g} / 10 \mathrm{~min}$ $\left(230^{\circ} \mathrm{C}, 7 \mathrm{~kg}\right)$. It is produced by Exxon Mobile group and provided in a granular form.

- Poly vinylidene fluoride PVDF (Hylar 5000) with a density of $1,76 \mathrm{~g} / \mathrm{cm}^{3}$ and a melting temperature of $180{ }^{\circ} \mathrm{C}$. It was produced by Ausimont Company in Italy. And provided in a powder form.

- Low density polyethylene LDPE (LDPE 2402H0) with a density of $0.924 \mathrm{~g} / \mathrm{cm}^{3}$ and a melt flow index of $0.2 \mathrm{~g} / 10 \mathrm{~min}$ $\left(190^{\circ} \mathrm{C}, 2.16 \mathrm{~kg}\right)$. It is produced by Sabic company of Saudi Arabia and provided in a granular form.

- Zinc oxide $\mathrm{ZnO}\left(5.6 \mathrm{~g} / \mathrm{cm}^{3}\right)$, with particles size $<5 \mu \mathrm{m}$ and a high purity $99.999 \%$. is produced and supplied by Aldrich Company.
- Titanium dioxide $\mathrm{TiO}_{2}\left(4.0 \mathrm{~g} / \mathrm{cm}^{3}\right)$, with particles size of $0.3 \mu \mathrm{m}$ and a purity $\geq 92.0 \%$ is produced and supplied by Showa America Company.

- Alumina $\mathrm{Al}_{2} \mathrm{O}_{3}\left(3.94 \mathrm{~g} / \mathrm{cm}^{3}\right)$, with particles size $<10 \mu \mathrm{m}$ and a purity $\geq 99.99 \%$ is produced and supplied by Merck.

- Stearic acid $\left(\mathrm{CH}_{3}-\left(\mathrm{CH}_{2}\right)_{16}-\mathrm{COOH}\right)$ is a long-chain fatty acid with bulk density of $400-500 \mathrm{~kg} / \mathrm{m}^{3}$ and a purity $\geq 99 \%$ is produced by Merck.

\section{Nanocomposites Preparation}

Before the melt blending with different polymers, metal oxides were first co-mixed with the stearic acid using a grinder coffee in order to improve their compatibility with the polymeric matrix and to ensure their dispersion. The obtained mixture was added at $0.5,1$ and $2 \%$ to polymers using a Brabender plastograph.

The different prepared formulations are referenced in Table 1.

\section{Characterization \\ Morphology}

In order to evaluate the coverage effectiveness of the stearic acid to cover the filler nanoparticles, the atomic force microscopy (AFM) has been conducted using a AXIOSCOP 40 microscope with a frequency of $1 \mathrm{~Hz}$ and at a scale of 50 $\mu \mathrm{m}$. The RMS roughness (root-mean-square height deviation) of the samples was obtained directly from the software of the AFM.

\section{Wide angle $X$-ray diffraction (WAXS)}

Wide angle X-ray scattering (WAXS) experiments were performed using a Philips X'Pert MPD diffractometer equipped with a $\mathrm{CuK} \lambda_{1}(\lambda=1,5405 \mathrm{~nm})$ monochromator in the reflection mode. The following conditions were employed: $45 \mathrm{kV} ; 40 \mathrm{~mA}$; angular range: $5^{\circ}-60^{\circ}(2 \theta)$. The degree of crystallinity $\alpha_{\mathrm{WAXS}}$ of all samples was derived from the ratio of the area corresponding to the crystalline peaks to the total area of the diffractogram.

\section{Dielectric properties}

The dielectric measurements were carried out using Hioki $3532 \mathrm{Hi}$-Tester and using the four point method.

\section{RESULTS AND DISCUSSION}

\section{Atomic Force Microscopy AFM}

Figures 1, 2 and 3 present the AFM topographic images in $3 \mathrm{D}$ of the untreated and treated fillers, respectively.

Figure1 shows the AFM topographic images in $3 \mathrm{D}$ of the untreated and treated $\mathrm{TiO}_{2}$ respectively of the PVDF/ $\mathrm{TiO}_{2}$ nanocomposites. It is observed that the RMS value decreased (from $272 \mathbf{~ n m}$ for neat $\mathrm{TiO}_{2}$ to $180 \mathrm{~nm}$ for the treated one) indicating that the stearic acid passed to the molten state and covered the $\mathrm{TiO}_{2}$ particles. 
Table 1

Different polymer compositions with treated and untreated fillers

\begin{tabular}{|c|c|c|c|c|}
\hline $\mathrm{TiO}_{2}(\%)$ & $\mathbf{0}$ & 0.5 & 1 & 2 \\
\hline NanocompositesPVDF/ untreated $\mathrm{TiO}_{2}$ & $\mathrm{~F}$ & FU0.5 & FU1 & FU2 \\
\hline Nanocomposites PVDF/ treated $\mathrm{TiO}_{2}$ & $\mathrm{~F}$ & FT0.5 & FT1 & FT2 \\
\hline $\mathrm{ZnO}(\%)$ & $\mathbf{0}$ & 0.5 & 1 & 2 \\
\hline Nanocomposites $\mathrm{HDPE} /$ untreated $\mathrm{ZnO}$ & $\mathrm{H}$ & HU0.5 & HU1 & HU2 \\
\hline Nanocomposites HDPE/ treated ZnO & $\mathrm{H}$ & HT0.5 & HT1 & HT2 \\
\hline $\mathrm{Al}_{2} \mathrm{O}_{3}(\%)$ & $\mathbf{0}$ & 0.5 & 1 & 2 \\
\hline Nanocomposites LDPE/ untreated $\mathbf{A l}_{2} \mathbf{O}_{3}$ & $\mathrm{~L}$ & LU0.5 & LU1 & LU2 \\
\hline Nanocomposites LDPE/ treated $\mathbf{A l}_{2} \mathbf{O}_{3}$ & $\mathrm{~L}$ & LT0.5 & LT1 & LT2 \\
\hline
\end{tabular}

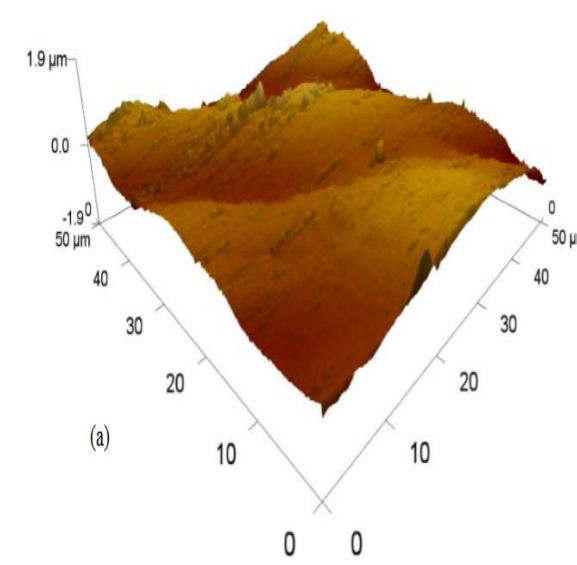

(a)

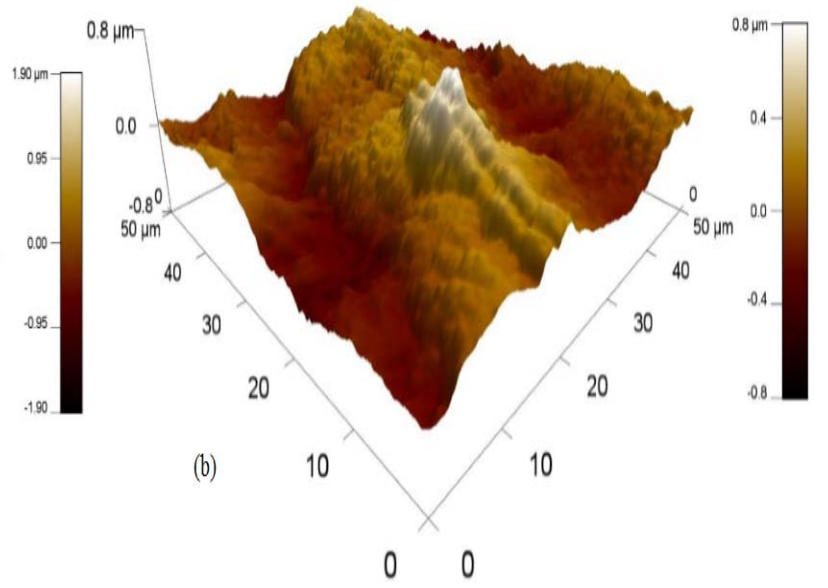

(b)

Fig. 1 - AFM topographic images three dimensions of the untreated $\mathrm{TiO}_{2}(\mathrm{a})$ and the treated one (b).

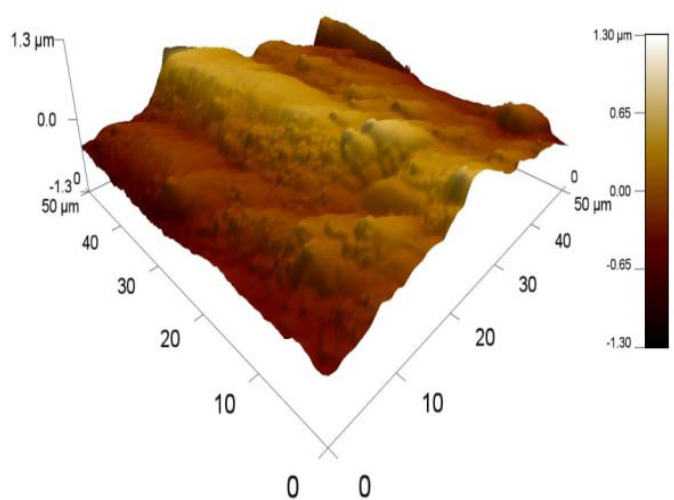

(a)

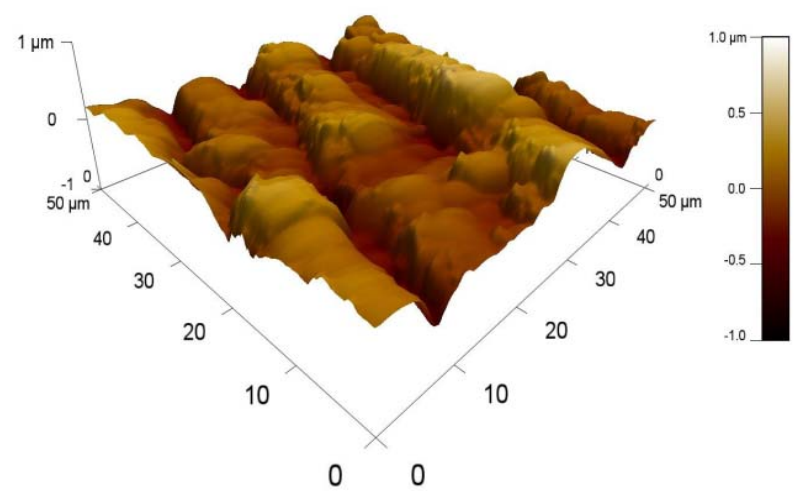

(b)

Fig. 2 - AFM topographic images three dimensions of the untreated $\mathrm{ZnO}$ (a) and the treated one (b).

Figure 2 presents the AFM topographic images in $3 \mathrm{D}$ of the untreated and treated $\mathrm{ZnO}$, respectively. It is observed that the RMS value decreased (from 254nmfor neat $\mathrm{ZnO}$ to $185 \mathrm{~nm}$ for treated one). The molten state of the $\mathrm{ZnO}$ ensures an excellent dispersion of the treated filler into the matrix.

Figure 3 presents the AFM topographic images in $3 \mathrm{D}$ of the untreated and treated $\mathrm{Al}_{2} \mathrm{O}_{3}$, respectively. It is observed that the RMS value decreased (from $334 \mathbf{n m}$ for neat $\mathrm{Al}_{2} \mathrm{O}_{3}$ to $63 \mathbf{~ n m}$ for treated one). The RMS value has decreased when the feed has undergone the treatment; this is explained by the fact that when the stearic acid melts it has made it possible to coat the $\mathrm{Al}_{2} \mathrm{O}_{3}$ particles. The latter has also generated an increase in the homogeneity of the surface. 


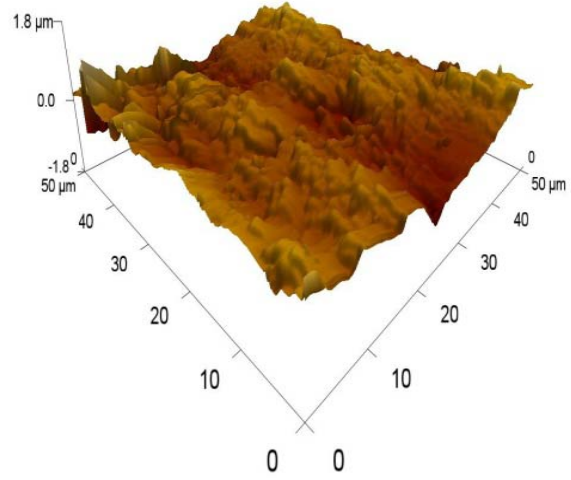

(a)
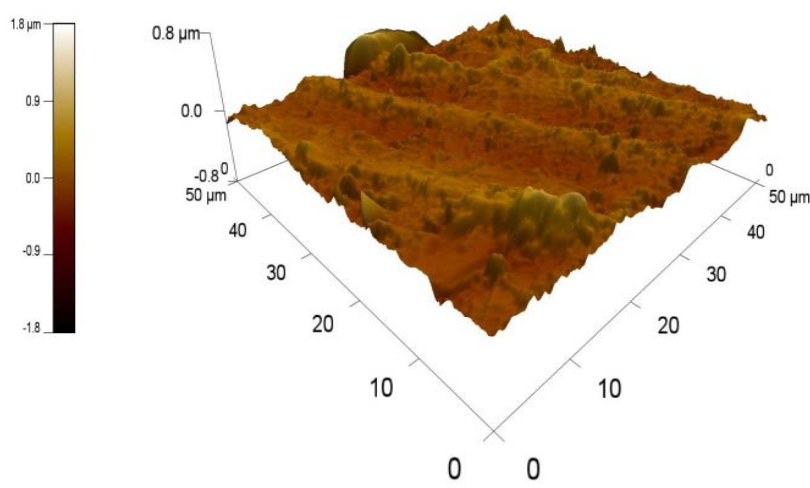

(b)

Fig. 3 - AFM topographic images three dimensions of the untreated $\mathrm{Al}_{2} \mathrm{O}_{3}(\mathrm{a})$ and the treated one (b).

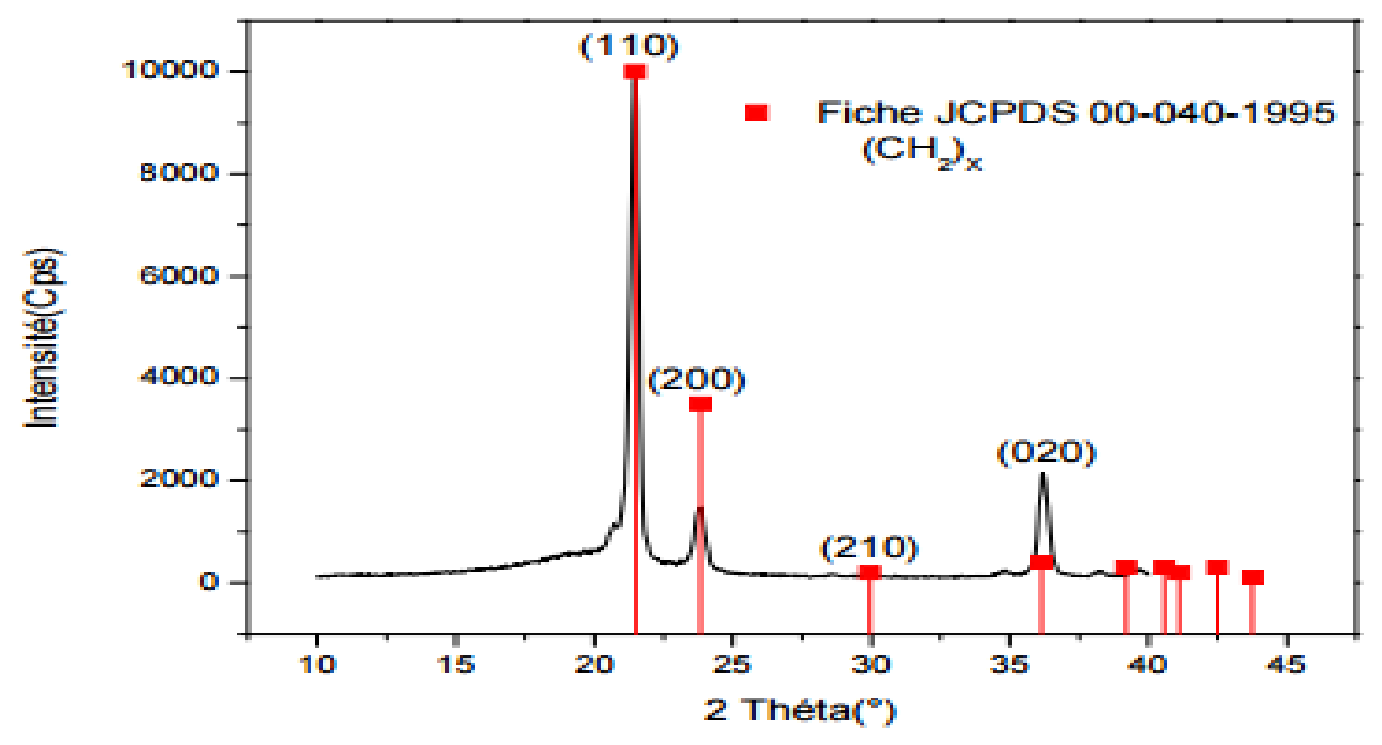

Fig. 4 - XRD pattern of pure $\mathrm{HDPE}^{12}$.

\section{Wide angle X-ray diffraction (WAXS)}

Figure 4 illustrates the X-ray diffraction pattern (XRD) of the pure high density polyethylene (HDPE) sample. ${ }^{12}$ It shows a strong peak appearing at $21.5^{\circ}$ and three moderately strong peaks at $23.9^{\circ}, 30^{\circ}$ and $36.2^{\circ}$ corresponding to the inter planner spacing of 4.132, 3.707 and $2.481 \AA$ respectively. These peaks correspond to the (110), (200) and (020) lattice planes.

Figure $5^{13}$ presents the XRD pattern for pure Zinc oxide $(\mathrm{ZnO})$ sample. The peaks, at scattering angles $2 \theta=31.68^{\circ}, 34.4^{\circ}, 36.16^{\circ}, 47.52^{\circ}, 56.48^{\circ}$, $62.88^{\circ}, 66.24^{\circ}, 67.84^{\circ}, 68.96^{\circ}, 72.48^{\circ}$ and $76.8^{\circ}$ correspond to reflections from: 100, 002, 101, 102, 110, 103, 200, 112, 201, 004 and 202 crystal planes.
Figure 6 presents the X-ray diffraction pattern (XRD) for $\mathrm{HDPE} / \mathrm{ZnO}$ nanocomposite films at 1 wt. \% $\mathrm{ZnO}$. A total disappearance of various characteristic peaks of the $\mathrm{ZnO}$ in the untreated and the treated compositions is shown. This result reflects the excellent dispersion of the filler in the polymeric matrix and the formation of the nanocomposites.

Figure 7 presents the X-ray diffraction pattern (XRD) for pure poly vinylidene fluoride (PVDF) sample. The XRD pattern shows that the peaks at $2 \theta$ corresponding to $18.5^{\circ}$, and 26.5 ) present in XRD pattern indicates the presence of $\alpha$-phase but the presence of high intense peak at $20.2^{\circ}$ confirms the presence of $\beta$-phase in PVDF film. ${ }^{14}$ The other XRD peaks at $36.1^{\circ}, 43.2^{\circ}$ and $57.4^{\circ}$ are indexed to the corresponding $\beta$-phase of PVDF film and $\alpha$ phase corresponding to $39.5^{\circ}$ and $48.6^{\circ}$. 


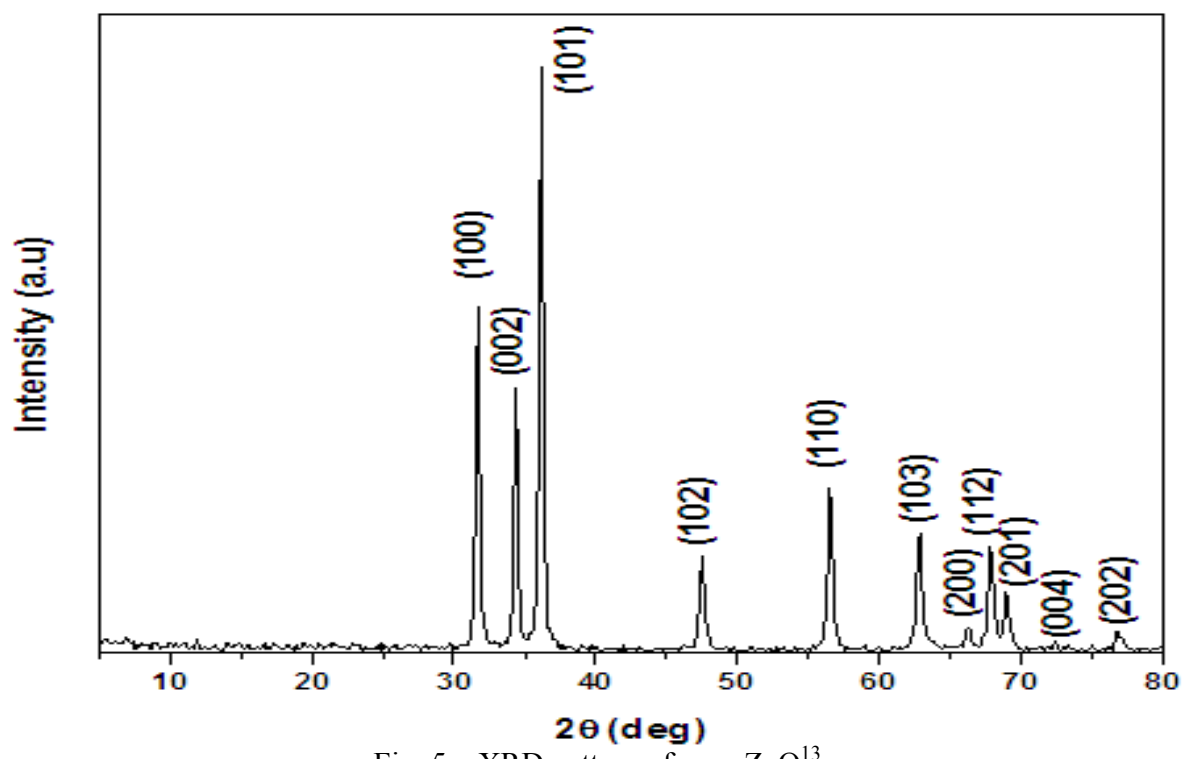

Fig. 5 - XRD pattern of pure $\mathrm{ZnO}^{13}$.

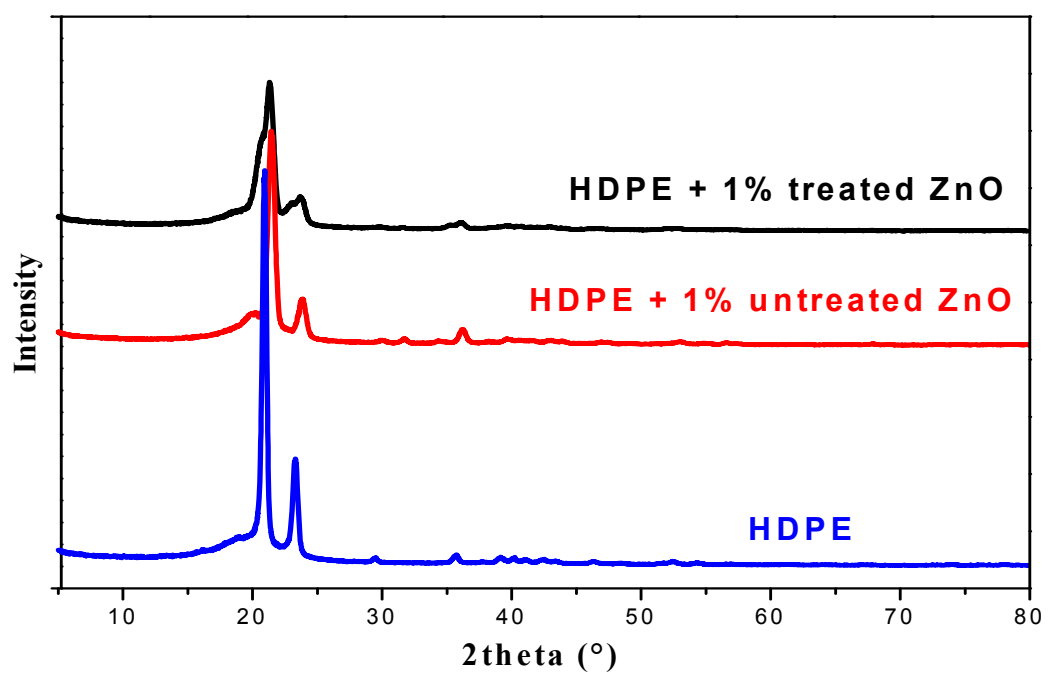

Fig. 6 - XRD pattern of pure HDPE and the HDPE/treated and untreated $\mathrm{ZnO}$ nanocompositions.

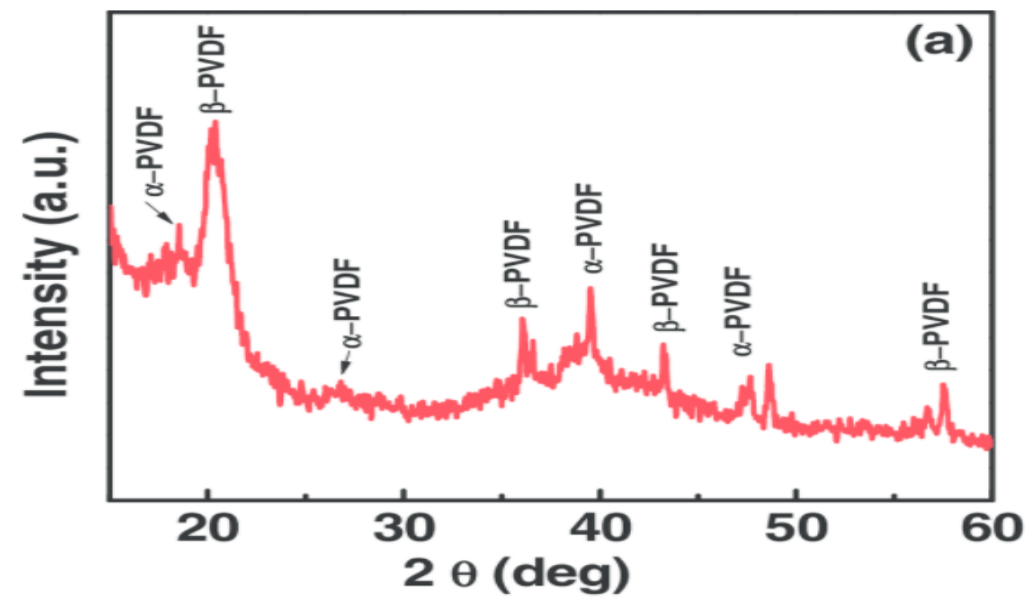

Fig. 7 - XRD pattern of pure $\mathrm{PVDF}^{14}$. 


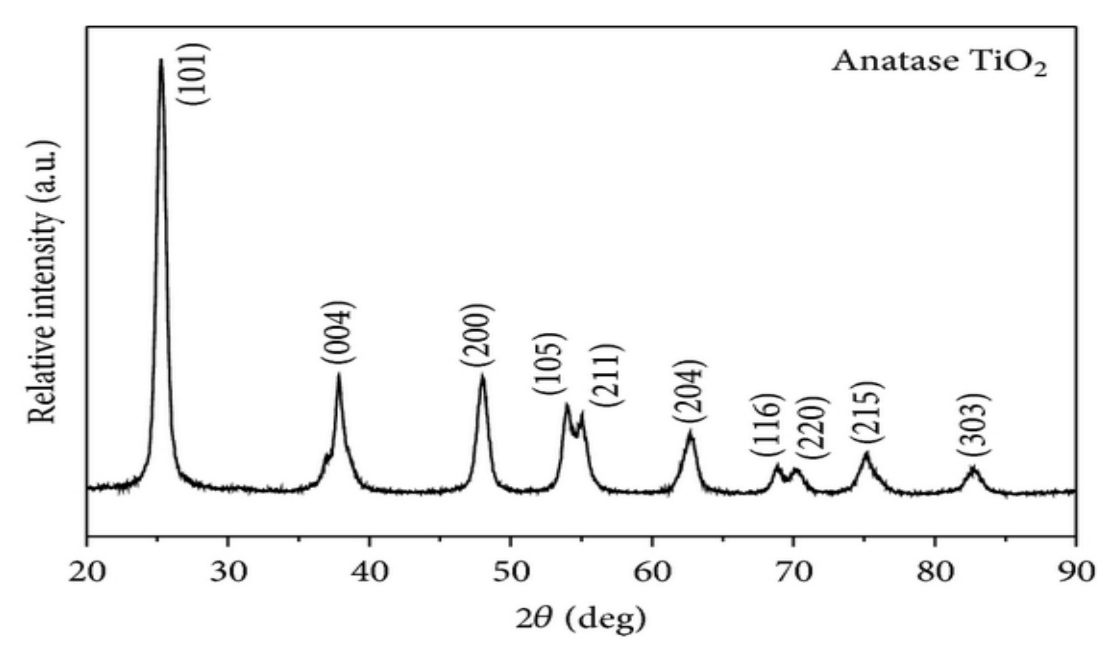

Fig. 8 - XRD pattern of pure $\mathrm{TiO}_{2}{ }^{15}$.

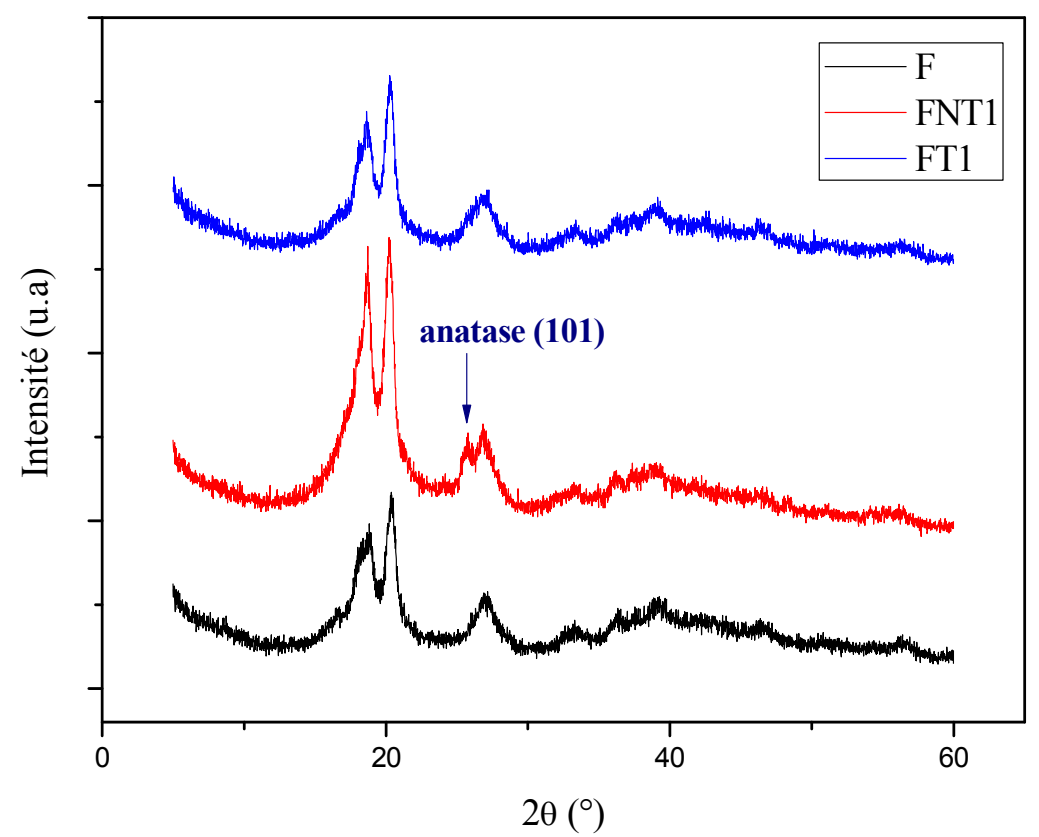

Fig. 9 - XRD pattern of pure PVDF and the PVDF/treated and untreated $\mathrm{TiO}_{2}$ nanocompositions.

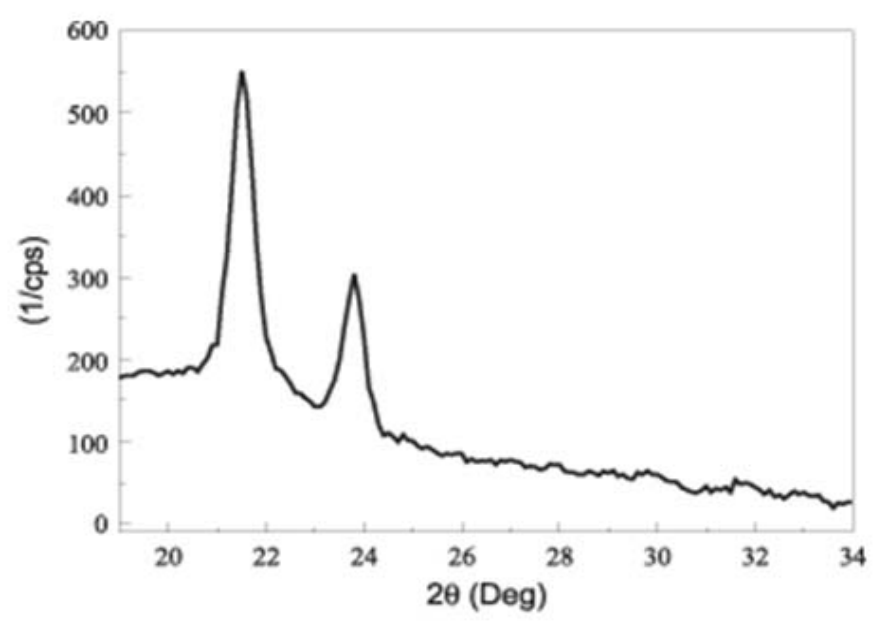

Fig. $10-\mathrm{XRD}$ pattern of pure $\mathrm{LDPE}^{16}$. 
Figure 8 presents the XRD pattern for pure Titanium dioxide $\left(\mathrm{TiO}_{2}\right)$. The peaks are identified to corresponding to (101), (004), (200), (105), (211), (204), (116), (220), (215), and (303) crystal planes. All diffraction peaks are well defined and can be perfectly assigned to the anatase $\mathrm{TiO}_{2}{ }^{15}$

Figure 9 shows the $\mathrm{X}$-ray diffraction pattern (XRD) for $\mathrm{PVDF} / \mathrm{TiO}_{2}$ nanocomposite films at 1 wt. $\% \mathrm{TiO}_{2}$. The peaks are identified corresponding to $(020),(101)+(110)$ and $(022)+$
(021) which are in convolution of the two phases $(\gamma+\alpha)$ of PVDF.

Figure 10 presents the $\mathrm{X}$-ray diffraction pattern (XRD) for pure low density polyethylene (LDPE) sample. ${ }^{16}$ The XRD pattern shows strong peaks appearing at $21.5^{\circ}$ and $23.8^{\circ}$ corresponding to the reticular planes (110) and (020) respectively.

Figure 11 presents the XRD pattern for pure Alumina $\left(\mathrm{Al}_{2} \mathrm{O}_{3}\right)$. The peaks are identified to corresponding to (101).

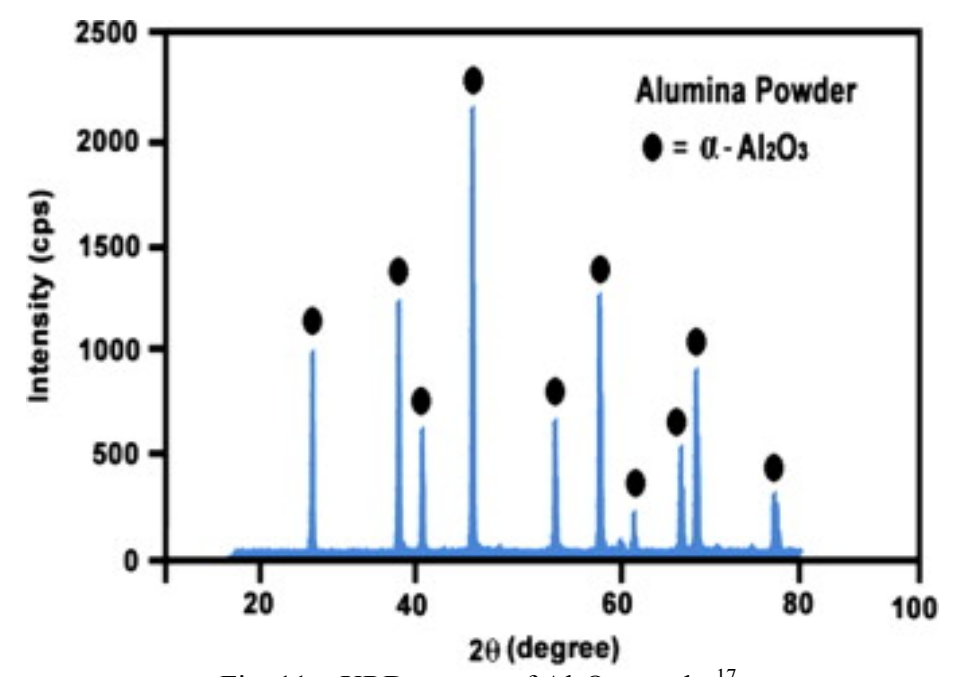

Fig. 11 - XRD pattern of $\mathrm{Al}_{2} \mathrm{O}_{3}$ powder ${ }^{17}$.

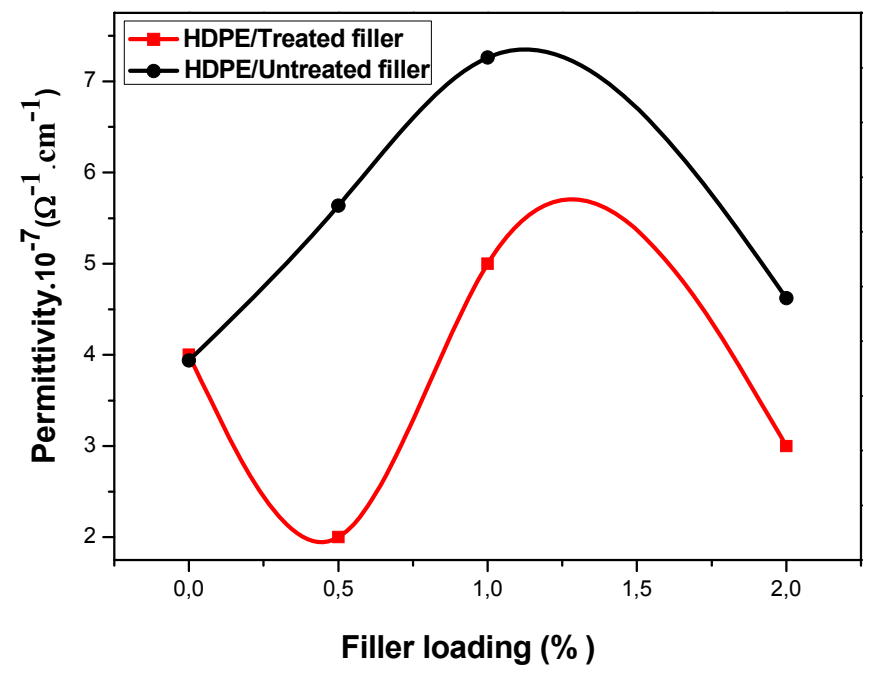

Fig. 12 - Variation of dielectric permittivity of HDPE / untreated and treated.

\section{Dielectric properties}

Figures 12-14 show the dielectric constant of the used polymers/fillers nanocomposites.

Figure 12 shows the dielectric constant of the HDPE/untreated $\mathrm{ZnO}$ nanocomposites. The conductivity of the polymeric matrix is enhanced due to the incorporation of $\mathrm{ZnO}{ }^{18}$ This result can be explained by the generation of the free electrons. ${ }^{18}$ It is observed that the $1 \%$ wt concentration of $\mathrm{ZnO}$ has the highest improvement.

Concerning the nanocomposites HDPE/treated $\mathrm{ZnO}$, the results are shown in the Figure12 which indicated that the highest value was at a treated $\mathrm{ZnO}$ concentration of $1 \% \mathrm{wt}$ and the lowest one at $0.5 \%$ wt. 


\section{ZnO nanocomposites as a function of the filler loading ${ }^{18}$}

Figure 13 shows the dielectric constant of the $\mathrm{PVDF} /$ untreated $\mathrm{TiO}_{2}$ nanocomposites. The inorganic nanofillers have a strong influence on the permittivity of resulting nanocomposites.

It can be seen that the dielectric constant of the composites increases with the increase of the filler load then decrease with an optimum of 3.63 . $10^{-7} \Omega^{-1} \cdot \mathrm{cm}^{-1}$ at $2 \%$ of the untreated filler and it is about $2.55 \cdot 10^{-7} \Omega^{-1} \cdot \mathrm{cm}^{-1}$ at $1 \%$ of the untreated one.

However, for the treated compositions, the electrical conductivity decreases with the addition of $0.5 \% \mathrm{TiO} 2$ to a minimum value of 1.22 .10 $7 \Omega^{-1} \cdot \mathrm{cm}^{-1}$, then increases to a maximum value of $2.55 \times 10-7 \Omega^{-1} \cdot \mathrm{cm}^{-1}$ with $1 \% \mathrm{TiO}_{2}$ and then decreases again with a level of $2 \% \mathrm{TiO}_{2}$.

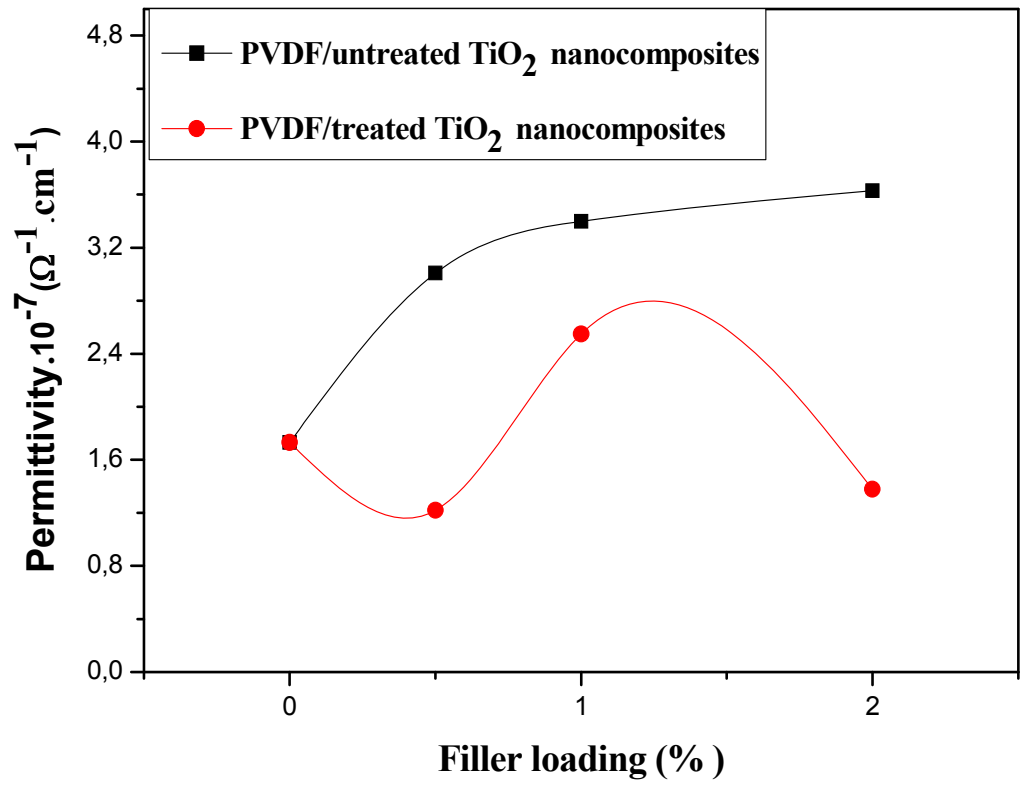

Fig. 13 - Variation of dielectric permittivity of PVDF / untreated and treated $\mathrm{TiO}_{2}$ nanocomposites as a function of the filler loading.

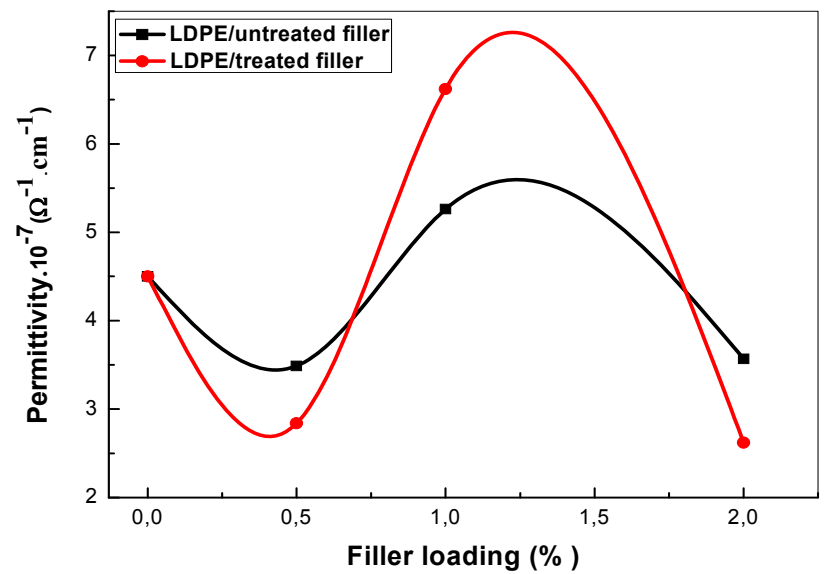

Fig. 14 - Variation of dielectric permittivity of LDPE / untreated and treated $\mathrm{Al}_{2} \mathrm{O}_{3}$ nanocomposites as a function of the filler loading.

Figure 14 shows the dielectric constant of the LDPE/untreated $\mathrm{Al}_{2} \mathrm{O}_{3}$ nanocomposites.

The inorganic nanofillers have a strong influence on the permittivity of resulting composites. ${ }^{3}$ It can be seen that the composites values increase with the increase of the filler load then decrease with an optimum of $5 \cdot 3 \cdot 10^{-7} \Omega^{-1} \cdot \mathrm{cm}^{-1}$ at $1 \%$ of the untreated filler and $6 \cdot 6 \cdot 10^{-7} \Omega^{-1} \cdot \mathrm{cm}^{-1}$ for the treated one. 


\section{CONCLUSIONS}

Polymers/metal oxides nanocomposites with treated and untreated fillers were successfully fabricated using the coffee grinder for fillers grinding, the co-mixing technique to treat fillers with stearic acid and the plastograph for polymer/metal oxides nanocomposite elaboration.

The morphology results showed that, the stearic acid has covered the filler nanoparticles and ensure an excellent dispersion of the treated and treated fillers into the polymeric matrix. This indicates the efficiency of the used method.

The XRD analysis indicated that for $1 \% \mathrm{wt}$ $\mathrm{ZnO}$ content, a total disappearance of various characteristic peaks of the untreated and treated $\mathrm{ZnO}$ in the HDPE/ZnO nanocomposite has been showed.

For the PVDF $/ \mathrm{TiO}_{2}$ nanocomposites, results showed that there are two phases $(\gamma+\alpha)$ of PVDF which are in convolution.

Finally, for the dielectric properties, the results showed that the conductivity of HDPE matrix enhanced with untreated $\mathrm{ZnO}$ nanoparticles, by its free electrons, and the concentration $\mathrm{ZnO}$ (1wt.\%) has the highest value.

For the $\mathrm{PVDF} / \mathrm{TiO}_{2}$ nanocomposites, the results showed that the highest value was observed at 2 wt. $\%$ of $\mathrm{TiO}_{2}$ for the untreated compositions and at $1 \mathrm{wt} . \%$ of $\mathrm{TiO}_{2}$ for the treated ones.

Concerning the LDPE/ $\mathrm{Al}_{2} \mathrm{O}_{3}$ nanocomposites, the results showed that the highest value was observed at 1 wt. $\%$ of $\mathrm{Al}_{2} \mathrm{O}_{3}$ for the untreated and the treated compositions.

As a comparation between electrical results of different composites, it has been observed that metal oxides enhanced the polymers conductivity. The highest value of treated $\mathrm{ZnO}, \mathrm{TiO}_{2}$ and was $\mathrm{Al}_{2} \mathrm{O}_{3}$ at $1 \mathrm{wt} . \%$.

\section{REFERENCES}

1. M. F. Abdrahman, S. Abdul Rashid and N. Abdul Rahman, ARPN J. Engineer. Appl. Scie., 2016, 11, 12073-12077.

2. J. A. Rodríguez and M. Fernández-García, Synthesis, Properties and Applications of Oxide Nanoparticles", Whiley: New Jersey, 2007.

3. F. Z. Benabid, O. K. Mallem, F. Zouai, M. E. Cagiao and D. Benachour, S. Afr. J. Chem., 2018, 71, 150-154.

4. J. Muscat, V. Swamy and N. M. Harrison, Phys. Rev. B., 2002, 65, 224112-224118.

5. X. Wang, Y. Ding, C. J. Summers and Z. L. Wang, J.Phys. Chem.B, 2004, 108, 8773-8777.

6. F. Z. Benabid, N. Kharchi, F. Zouai, A.-H. Mourad and D. Benachour, Polymers \& Polymer Composites, 2019, 27, 389-399.

7. S. Singha and M. J. Thomas, IEEE Trans. Dielectr. Electr. Ins., 2009, 16, 1070-9878.

8. A. Fazilah, M. Maizura, A. Abd Karim, K. Bhupinder, B. Rajeev, U. Uthumporn and S. H. Chew, Int. Food Res. $J ., 2011,18,1027-1033$.

9. A. S. A. Khiar and A. K. Arof, World Aca. Sci. Eng. Tech., 2011, 59, 23-27.

10. F. Zouai, F. Z. Benabid, S. Bouhelal, M. E. Cagiao, D. Benachour and F. J. Baltá Calleja, J. Mater. Sci., 2017, 52, 4345-4355.

11. F. Z Benabid, L. Rong, D. Benachour, M. E. Cagiao, M. Ponçot, F. Zouai, S. Bouhelal and F. J. Baltá Calleja, J. Polym. Eng., 2015, 35, 181-190.

12. N. Parvin, M. D. Samir Ullah, M. D. Forhad Mina and M. D. Abdul Gafur, J. Bangladesh Acad. Sci, 2013, 37, 11-20.

13. Etude du comportement du polyéthylène haute densité sous irradiation ultraviolettes ou sollicitation mécanique par spéctroscopie de fluorescence. [En ligne]. Disponible sur : <tel.archives-ouvertes.fr/tel-00541017/document>. Consulté le (25/05/2015).

14. P. Singh, H. Borkar, B. P. Singh, V. N. Singh and A. Kumar, AIP Advances, 2014, 4, 087117-087122.

15. X. Wei, G. Zhu, J. Fang and J. Chen, Int. J. Photoenergy, 2013, Article ID 726872, 6 pages.

16. L. H. Poley, A. P. L. Siqueira, M. G. da Silva, H. Vargas and R. Sanchez, Polímeros, 2004, 14, 8-12.

17. D. Thirumalaikumarasamy, K. Shanmugama and V. Balasubramanian, Progress in Nat. Sci.: Mater. Int., 2012, 22, 468-479.

18. F. Z. Benabid, N. Kharchi, F.Zouai, Abdel-Hamid. I. Mourad and D. Benachour, Polymers and Polymer Composites, 2019, 27, 389-399. 
